\title{
Um Títere de Si Mesmo: Reinventando Processos de Colaboração entre Criadores
}

\author{
Lisandro Bellotto ${ }^{1}$ \\ Marta Isaacsson ${ }^{2}$
}

\begin{abstract}
Resumo:
O estudo apresenta o processo de criação de $U m$ Titere de si mesmo, performance que investe na relação do corpo com a imagem virtual. Discutese aqui a singularidade da forma adotada no processo de criação para o compartilhamento de materiais sensíveis entre os criadores envolvidos. A aposta na criação de uma dinâmica de colaboração na qual a dependência e a autonomia criativa contribuem para a composição de um hipertexto cênico.
\end{abstract}

Palavras- Chave: tecnologia, hipertexto, virtual, imagem.

\begin{abstract}
:
The study presents the creation process of $\mathrm{A}$ puppet of himself, performance that invests in the relation of body with the virtual image. It is argued here the uniqueness of the form adopted in the creation process for sharing sensitive materials between the creators involved. The focus on creating a dynamic collaboration in which the dependence and the creative autonomy contribute to the composition of scenic hypertext.
\end{abstract}

Keywords: tecnology, hypertext, virtual, image.

1 Mestre em Teatro pelo Programa de Pós-Graduação em Artes Cênicas da UFRGS. Cia Rústica, e a Cia Espaço em Branco. E-mail: lisandrobellotto@yahoo.com.br

2 Professora doutora do Programa de Pós-Graduação em Artes Cênicas da Universidade Federal do Rio Grande do Sul. E-mail: missilva@portoweb.com.br 
Com intuito de partilhar neste espaço uma pesquisa-criação, iniciamos lembrando que a pesquisa em arte requer sempre inovação de procedimentos metodológicos e/ou de matérias expressivas. Esses constituíram os propósitos da pesquisa-criação que resultou na obra cênica Um Títere de Si Mesmo, protagonizada por Lisandro Bellotto, no âmbito do curso de mestrado do Programa de Pós-Graduação em Artes Cênicas da UFRGS. Além do desejo de criar uma obra que refletisse as relações das artes da cena que incorporam os dispositivos tecnológicos, colocando o corpo do performer em diálogo com seus duplos de luz projetados no palco, como títeres de sua própria imagem, o desafio consistia em construir uma obra a partir de uma matéria sensível proposta por todos os criadores. E aqui não é mera coincidência a semelhança com o "objeto sensível" que marca a origem dos processos de criação sob o "Cycle du Répère" ${ }^{11}$, muito empregado por Robert Lepage. Longe do texto dramático, de um roteiro, de uma trama pré-estabelecida, o "objeto sensível" constitui um material com a potência suficiente de, explorado em livre associação, gerar ações criativas e destacar temáticas.

No intuito de compor essa matéria/objeto sensível, entendeu-se ser pertinente investir em uma nova modalidade de colaboração entre os criadores. A proposta não era estabelecer um processo de criação coletiva, pois deveria se manter o respeito à especialização das funções, nem um processo colaborativo sob a forma mais habitual. Isso porque, embora a proposta fosse uma horizontalidade nas relações criativas, a troca entre criadores deveria se fazer, inicialmente, por meio da tecnologia e não da forma direta como ocorrem nos processos colaborativos tradicionais. Afinal, diferentes maneiras de compartilhar estão surgindo no mundo, em virtude do progresso da tecnociência. É preciso considerar que, à medida que a ciência progride, os dispositivos tecnológicos se tornam mais eficientes, leves, potentes, miniaturizados e extremamente maleáveis, à custos cada vez mais baixos. Consequentemente, seus agenciamentos contaminam todos os campos dos saberes e provocam profundas transformações em sociedade, afetando a maioria das pessoas, direta ou indiretamente, transcendendo o uso particular que se faz das máquinas, tornando-as meios de coletivização social, como o uso em escala global do ciberespaço. Graças à revolução da informação e da comunicação, os equipamentos tecnológicos são cada vez mais onipresentes nas relações entre os homens.

Assim, é um caminho natural e irreversível (re)inventar novas formas de se conviver e produzir no coletivo, como resultado das nossas percepções que estão sendo estruturadas pelos novos meios. Nesse sentido, uma forma singular de diálogo artístico foi instituída entre os criadores na pesquisa-criação Um Títere de si mesmo, ou seja entre o performer Lisandro Bellotto, o artista visual Leonardo Remor ${ }^{2}$ e o músico Felipe Gue Martini ${ }^{3}$.

1 Processo de criação desenvolvido no Théâtre de Repère, dirigido por Jacques Lessard, onde Robert Lepage começou sua carreira. Trata-se de um sistema que tem por início a criação de uma partitura exploratória construída pelo mote de um objeto e por meio de improvisações, fundadas nas interpretações subjetivas e na sensibilidade do(s) criador(es). À partitura exploratória segue-se a avaliação (quando são identificados os temas emergentes) e, posteriormente, a criação da partitura sintética do espetáculo.

2 Leonardo Remor é bacharel em comunicação social, com habilitação em Realização Audiovisual pela UNISINOS (2008), e especialização em Direção de Arte e Animação. Suas criações fílmicas privilegiam o experimento e a mistura das linguagens cinematográficas, que mesclam os gêneros de ficção, documentário e animação. É o caso dos curtas "Sempre partir" (2014) e "Sobre um Dia Qualquer" (2009). Atua também como fotógrafo, tendo realizado diversas exposições na cidade de Porto Alegre. Se aproximou do teatro através da criação dos vídeos para as peças Alice, da Cia Espaço em Branco(2009), e Miragem(2013) da Cia Rústica de teatro, ambas sediadas na cidade de Porto Alegre.

3 Felipe Gue Martini é músico autoditada, tem graduação em Jornalismo e mestrado em Comunicação pela UNISINOS/RS. É Especialista em Projeto Sociais e Culturais pela UFRGS, e professor dos cursos de bacharelado em Jornalismo e Publicidade/ Propaganda - Faculdade América Latina(Caxias do Sul-RS). Realizou a trilha sonora de filmes de curta-metragem como, "Gigante de Ferro: A ferrovia do trigo", dirigido por Matheus Butzke Picolli e "Inevitável Mundo Novo", dirigido por Boca Migotto. Produziu, interpretou e compôs os temas e arranjos do seu álbum: "No Descompasso do Transe Retalhos do Meu Silêncio, disco lançado em 2004 pela gravadora Amplitude 
Desta forma, antes de constituir elemento de composição cênica, o uso da tecnologia se colocou como agenciador fundamental do processo criativo. A interface oferecida pelo computador passou a constituir o espaço capaz de promover intercâmbio criativo entre os membros da equipe artística, ao longo do percurso de desenvolvimento da matéria sensível. Cabe esclarecer que o termo interface originalmente surgiu com os adaptadores de plugue usados para conectar circuitos eletrônicos. Todavia, como ressalta Lúcia Santaella o emprego feito hoje em dia do conceito de interface vai muito além, abrangendo desde cabos e conectores até encontros pessoais e a fusão de corporações financeiras:

Uma interface ocorre quando uma ou mais fontes de informação se encontram face a face, mesmo que seja o encontro da face de uma pessoa com a face de uma tela [...] são zonas fronteiriças sensíveis de negociação entre o humano e o maquínico. (SANTAELLA, 2003, p.91-92).

Assim, a interface oferecida pelo computador, meio de conexão dos homens da era digital, assumiu, na primeira fase da pesquisa-criação, o lugar de desdobramentos criativos. O computador passou a ser entendido como espaço não só de interação, mas de multiplicação de pensamentos e sentidos, possibilitando o desenvolvimento de uma obra coletiva, alimentada por dados em um processo de fluxo contínuo entre as faces.

Dentro desse modelo de interação entre criadores, cabia encontrar algo que mediasse suas relações, estimulando-os à produção de materiais a serem experimentados posteriormente em cena. A aposta foi investir na imagem. Isso porque como diz Lehmann (1999), "na civilização midiática pós-moderna, a imagem representa um meio extraordinariamente poderoso, mais informativo que a música, consumido mais rapidamente que a escrita" (p. 365).

As imagens tecnológicas disponíveis na rede ganharam então um interesse particular no processo de criação. Na realidade, o espaço da rede pode ser considerado uma espécie de inconsciente coletivo, pois nele há um repositório de memórias do homem. Afinal, a cultura da internet, ou cybercultura ou ainda cultura digital, resulta da interferência de uma grande comunidade virtual, constituída de pessoas de diversas nacionalidades que realizam trocas ilimitadas e constantes de informações. No espaço virtual, os dados são diversos e outros meios encontramse reunidos, desde livros, jornais, revistas, até programas televisivos, radiofônicos, cinema, vídeo, música ou qualquer outro gênero de informação traduzidos em uma mesma linguagem. É uma fonte muita rica de estímulos visuais e sonoros em escala global.

A pesquisa-criação em estudo teve início no compartilhamento de imagens pela interface disponibilizada pelo computador, despertando associações, unindo, questionando, estimulando, desafiando e impelindo os artistas a criarem os primeiros materiais que seriam explorados em cena. Ao longo do diálogo entre criadores, a imagem assumiu diferentes formas: imagem visual, imagempalavra e imagem-sonora. Em termos operacionais, a primeira fase do processo consistiu na escolha pelo performer de imagens difundidas na rede. Nesse momento, poderia ser selecionada qualquer tipo de imagem, oriunda de qualquer lugar do hipertexto digital. O performer pesquisador navegava nas ondas da web ou " $w w w$ ", parte multimídia da internet que permite visitar as homepages, usando a prática da deriva, zapeando pelos sites randomicamente, saltando de janela em janela, jogando aleatoriamente palavras em sites de buscas e aceitando sugestões dos internautas em chats de bate papo. Desse procedimento chegaram imagens por todos os lados do mundo virtual. Dezenas 
de imagens, das quais muitas delas não diziam nada ao performer, eram indiferentes, pareciam mudas para o olhar. No entanto algumas, ao colorirem o monitor arrebatavam despertando emoções, inquietando os pensamentos, suscitavam recordações dolorosas ou causavam fascínio pelo teor dramático ou indefinível.

As imagens foram pouco a pouco sendo selecionadas pelo performer em razão das provocações geradas em si próprio, do real interesse que lhe despertavam, dos mundos significantes e afetivos do imaginário que lhe convocavam. Um processo subjetivo, tão crítico como apaixonado, similar aquele vivenciado pelo filósofo francês Roland Barthes (1984) em sua escolha pelas imagens fotográficas que serviram à sua análise em A Câmara Clara. Nota sobre a fotografia:

Mais valia, de uma vez por todas, transformar em razão minha declaração de singularidade e tentar fazer da "antiga soberania do eu" (Nietzsche) um princípio heurístico. Resolvi tomar como ponto de partida de minha busca apenas algumas fotos, aquelas que eu estava certo de que existiam para mim. Nada a ver com um corpus: somente alguns corpos[...]aceitei então tornar-me por mediador de toda a fotografia. (p. 19).

Conduzido por movimentos pessoais na seleção, o performer elegeu seis imagens para deflagrar o jogo entre a equipe, entre as quais: $O$ rebelde desconhecido ${ }^{4}$, fotografado em Pequim por Jeff Widener em 1989; Execution fotografado em Saigon por Eddie Adams, em 1968; Seca no Mali, fotografado em 2007, por Sebastião Salgado (fig.1). Essas imagens percorreram o mundo e se encontram disponíveis no cyberespaço. Nesse sentido são de domínio público e trazem como referente corpos tensionados ao extremo, corpos em situações-limite. Imagens fortemente expressivas e que possuem um grande potencial de impacto afetivo. Fotografias que foram exibidas e exploradas exaustivamente pelos meios de comunicação e transformadas em símbolos da resistência a regimes opressores, da intolerância e da diferença de classes. Imagens violentas que carregam histórias que se perpetuam ainda nos dias de hoje. A fotografia traduz o real em estado passado, todavia, o homem segue cometendo as mesmas atrocidades e erros reproduzidos nas imagens escolhidas. Para analisar e fundamentar as imagens selecionadas pelo pesquisador, além das preferências pessoais, se recorreu a noção de punctum, definida assim por Roland Barthes (1984):

Algo que parte da cena, como uma flecha, e vem me trespassar. Em latim existe uma palavra para designar essa ferida, essa picada, essa marca feita por um instrumento pontudo; essa palavra me serviria em especial na medida em que remete também à idéia de pontuação e em que as fotos de que falo são, de fato, como que pontuadas, às vezes até mesmo mosqueadas, com esses pontos sensíveis; essas marcas, essas feridas são precisamente pontos [...] punctum é também picada, pequeno buraco, pequena mancha, pequeno corte $[. .$.$] o punctum de uma foto é esse acaso que, nela, me punge$ - mas também me mortifica, me fere. (p. 46).

Na fotografia o Rebelde Desconhecido o punctum e suas características identificadas pelo filósofo se desdobram em pelo menos três situações pungentes. A primeira diz respeito à diferença brutal do corpo humano e da máquina de guerra; desse lugar que torna a existência quase impossível em meio a toneladas de chumbo. A segunda é a presença de elementos díspares, como o tanque e a praça da Paz Celestial em Pequim; mundos heterogêneos que habitam a mesma imagem. O 4 Imagem digital disponível em: http://acertodecontas.blog.br/wp-content/uploads/2009/06/o-rebeldedesconhecido-de-tiananmen_jeff-widener.jpg. Último acesso em: 31/01/2014. 
terceiro diz respeito ao homem parado em frente aos tanques. Ele não morreu frente à fotografia, mas desapareceu misteriosamente, longe dos olhos das câmeras. O punctum agora é diferenciado dos anteriores, se dá em relação ao tempo, já que a fotografia ressuscita uma previsão de morte futura. Todos esses elementos suscitam nostalgia, repulsa e euforia; fazem calar diante do "rebelde" condenado pela fotografia.

Uma vez selecionada pelo performer, a imagem visual motivou a criação de uma imagempalavra. Observa-se aqui que essa transposição imagem-visual para imagem-palavra não obedeceu a princípios pré-estabelecidos, a não ser, mais uma vez, aquele da sensibilidade do performer. Assim, as imagens-palavras ganharam formas diversas. Se, por um lado, pequenos detalhes do conteúdo da imagem original apareciam descritos, por outro lado, o texto se configurava majoritariamente em uma escrita poética e subjetiva. Um campo poético que se descortinou em razão do trânsito de permeabilidade generalizada. Os vãos abertos entre as linguagens estão impregnados de virtualidades, onde o imaginário, o abstrato e o invisível constituem espaços destinados à pura criação artística. A fotografia saindo do quadro para permitir a adaptação da imagem ao espaço gráfico. Nesse caso, cada elemento que constitui as imagens, cada lugar, gesto, olhar, postura corporal ou objeto se traduz em desejo, ação, palavra e imaginação. Segundo Barthes (1984), a palavra tende para o ficcional, diferente da fotografia que autentica a si mesma. Essa tendência da palavra permitiu operar transformações que estenderam o olhar para além do que pode ser visto nas imagens. De forma que para Seca no Mali a escrita permitiu que se fizesse uma série de especulações acerca do menino e da árvore retratados: das origens dos elementos ao seus possíveis destinos. Tática semelhante utilizada para a imagem Execution; perscrutar as consequências das ações, somadas à descrição do espaço retratado. Os momentos de passagem de uma linguagem à outra, da imagem para a escrita pode ser entendido como uma espécie de oscilação entre dois pontos, onde se pretende caminhar em cima de uma linha tênue que separa mundos imbricados para sempre.

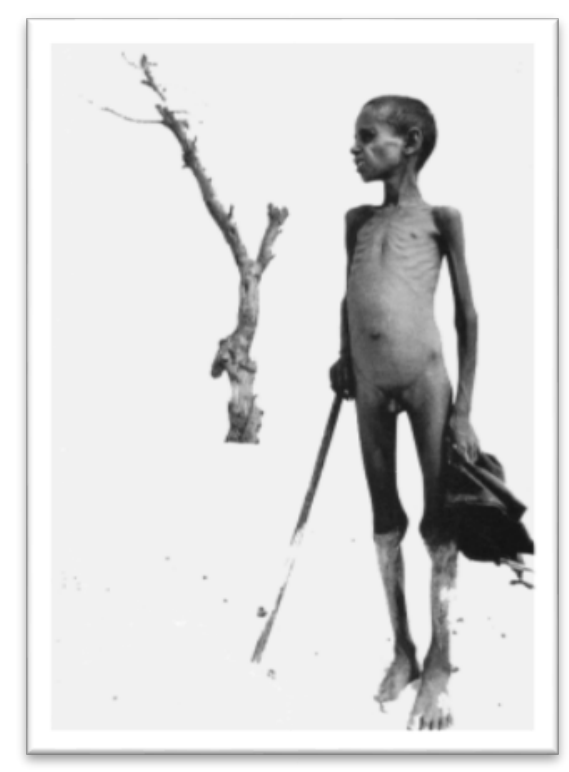

Fig. 1: Seca no Mali, Sahel/África, 1985. Autor: Sebastião Salgado 57

5 Imagem digital disponível em http://www.alangandy.com/sebastiao-salgado-seca-no-mali/ 
Desconhecendo as imagem visuais escolhidas pelo performer, o artista visual recebeu somente as imagens palavra, com a tarefa de propor novas imagens visuais. As narrativas serviram de base para ele procurar no cyberespaço imagens que traduzissem novamente as palavras escritas. Agora o texto, as palavras derramadas no monitor foram o pressuposto para a seleção de imagens que enriqueceram o conjunto de materiais sensíveis que, posteriormente, seriam explorados em cena. Um jogo de idas e vindas de texto e imagem se estabeleceu. As imagens selecionadas por ele foram batizadas de duplos e impressionam, por vezes, pela força associativa que elas estabelecem com as anteriores, por outras vezes, pelo acerto na escolha da mesma imagem. Para o texto da imagem Seca no Mali, ele escolheu uma fotografia plano-detalhe do rosto imundo e repleto de vermes de uma criança que chora (Fig.2). É tão chocante quanto a fotografia de Sebastião Salgado e revela plena sintonia com o drama agudo do menino que foi descrito na narrativa sobre a "Seca no Mali". $\mathrm{O}$ punctum do rosto desfigurado pelas condições de vida da figura é conservado nessa imagem, como que transferida de uma imagem a outra pela ponte da palavra. É da boca distorcida do menino que emana o grito silencioso da fotografia e que atinge quem contempla a imagem "em cheio". Barthes cita o escritor Ítalo Calvino para falar da máscara "como aquilo que designa uma face o produto de uma sociedade e de sua história" (BARTHES 1984:38). A essência do abandono e do desespero estão impressas nessas duas máscaras.

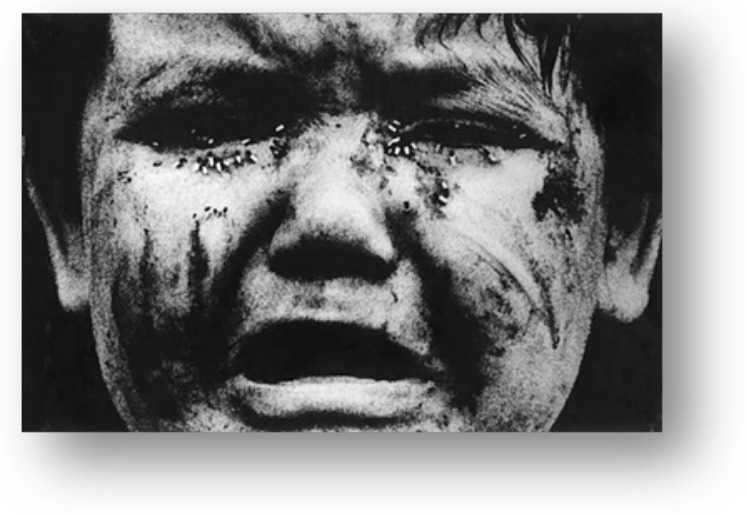

Fig. 2: Colonos, Rio Grande do Sul/RS, 1996. Autora: Jacqueline Joner ${ }^{6}$.

É pela pureza(ou crueza dilacerante) do sentido que torna a máscara algo tão agudo e que fere. Segundo o artista visual Remor:

A imagem da criança com os vermes, chorando, foi uma imagem que me marcou muito, foi uma professora minha que me mostrou, e que me ensinou a fotografar. Ela é fotojornalista e publicou a história dessa foto real, que tinha muita força e que estava na minha cabeça e, em algum momento, essa imagem, que já estava armazenada, se ligou a descrição da imagem do Sebastião Salgado. (REMOR, 2013).

Por sua vez, o músico de posse, exclusivamente, da imagem-visual proposta pelo artista visual, era convocado a compor uma imagem-sonora. O processo de composição sonora guarda semelhanças com os processos anteriores, uma vez que o músico, em processo poético, também estendeu seu $6 \quad$ Imagem digital disponível em :

http:/jacquelinejoner.com.br/Exposicoes/Pages/Colonos.html\#4. Último acesso em 28/01/2014. 
olhar para além do que podia ser visto nas imagens, interagindo, participando, fazendo parte delas e sobrepondo construções musicais às imagens:

Acho que a série de fotos escolhidas, algumas históricas, outras mais descontextualizadas, apresentaram questões diferentes. Em comum, para além das imagens em si, acho que o próprio ato de pensar sobre elas, sobre aqueles sentidos ali, sobre os personagens em quadro, fora de quadro, enfim, sobre o que está dito e o que está por dizer. Esses diálogos e silêncios que tentei preencher com sonoridade, como se estivesse conversando com elas. (MARTINI 2012)

A linguagem virtual do intercâmbio entre artistas interferiu nas composições, já que as sonoridades foram também estruturadas por esse meio. Como se a máquina conectada exigisse seu quinhão, resultando em uma musicalidade repleta de efeitos e distorções eletrônicas, nascidos das imagens.

Achei que a própria condição do trabalho (via digital) demandava certa linguagem, certo diálogo com elementos virtuais, com distúrbios, falhas, ruídos, interferências [...] Assim como todas as manipulações, recortes, baterias eletrônicas e samples. Imaginei que no caminho entre as imagens e eu, depois entre as músicas e o Lisandro, os arquivos poderiam se contaminar por outros arquivos da rede, adquirindo outras camadas, ganhando cargas, aderências, texturas, enfim, se modificando pelo trânsito não-linear da rede. Eles foram de Nova York e voltaram a Porto Alegre, de passagem pelo Mississipi, colou uma Nina Simone, um murmúrio de blues, uma gaita de boca. Essas coisas articuladas a algum sentido que eu pudesse compreender e aceitar como meu. (MARTINI 2012).

Assim, o processo de criação do material sensível se desenvolveu como uma contínua reescritura, motivada pelas potências criativas dos participantes, acionadas pela força sugestiva das imagens e suas diferentes possibilidades de leituras. A noção de palimpsesto proposta pelo francês Gerard Genette retrata o caminho percorrido, um "jogo palimpsestuoso", relacionando as diversas camadas das imagens isoladas. Ainda que Genette utilize a metáfora do pergaminho raspado para definir aspectos relacionais entre textos, aqui a metáfora transborda, se estende para o terreno das diferentes linguagens que se agenciam entre si, partindo de um mesmo ponto para criação do texto espetacular. O conteúdo de uma linguagem sendo evocada no conteúdo da linguagem seguinte. De forma que o texto ou imagem que se origina da anterior se transforma em hipotexto para a criação seguinte. É possível ler, por trás das "descrições textuais" as imagens que serviram de base para a escrita. Por sua vez, as imagens selecionadas pelo artista visual deixam a transparência dos textos correrem por trás das imagens que ele selecionou. O mesmo para as imagens sonoras, de forma que a tradução musical para a imagem Seca no Mali, por exemplo, ainda guarda algo da fotografia do Sebastião Salgado, que lhe deu origem.

A segunda fase do processo foi definida por ensaios, onde se operaram os cruzamentos das matérias propostas pelos artistas. O princípio adotado foi de transformar, multiplicar e agenciar o material sensível (imagético e sonoro), composto na fase anterior. Era necessário confrontar o passado das imagens com uma possível reconstrução delas no presente.

Nessa nova etapa, uma matéria expressiva interferia na outra a todo o momento pela mão dos pesquisadores, graças aos possíveis desdobramentos das imagens e sons. $\mathrm{O}$ artista visual elaborou 
ações videográficas inspiradas no repertório imagético disponível, o músico transformou seu material sonoro a partir do que observava nos ensaios, enquanto o performer improvisava em busca de um diálogo com as imagens virtuais de natureza diversas: imagens captadas ao vivo ou pré-gravadas; construídas sobre um retroprojetor ou difundidas pelos projetores digital e de slides. Um novo desafio se colocou nessa prática. Depois de usar a Internet e seus periféricos como propulsor para deflagrar o processo criativo via imagem, as mídias tecnológicas precisavam estar perfeitamente imbricadas na encenação e não se transformarem em meros aparatos ilustrativos. Uma das alternativas encontradas foi explorar a incrustação do plano real sobre o plano do virtual, graças a um jogo relacional entre a ação do performer e a imagem projetada. Assim, as imagens tridimensional e bidimensional se encontram em uma relação de entrelaçamento ou de causa-efeito, elaborando uma quadro cênico em movimento. Como o tiro fatal na tradução cênica da imagem Execution, onde o performer em cena dá um tiro em sua própria imagem projetada ao fundo.

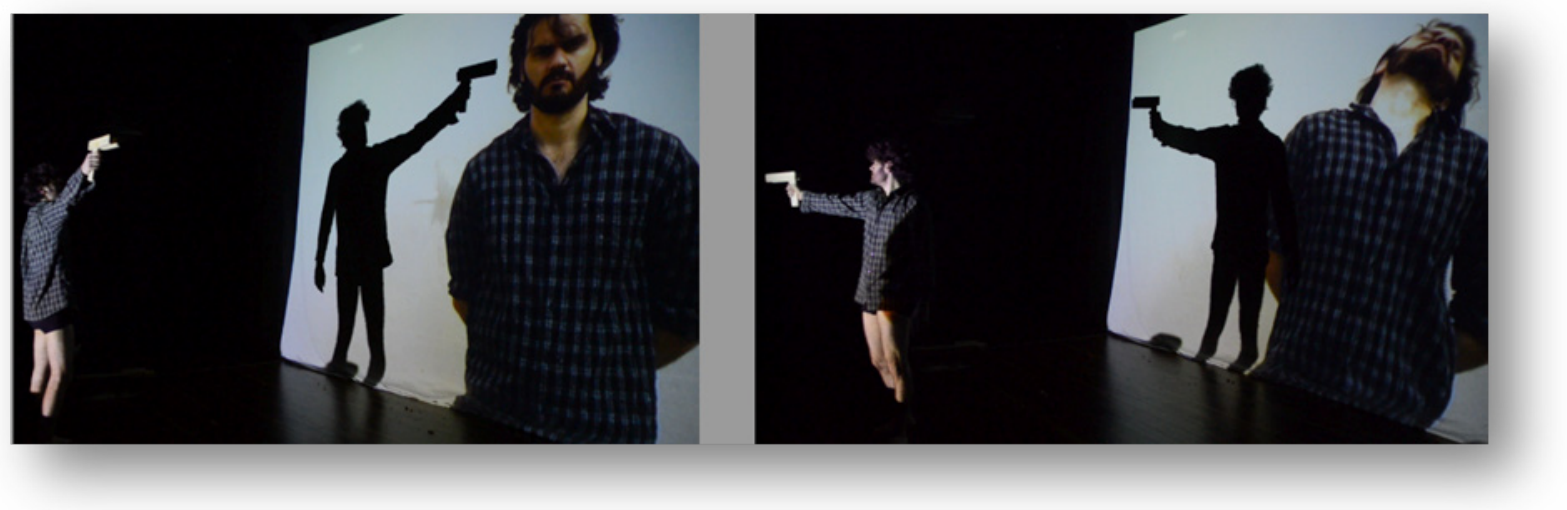

Fig. 3: Frames apresentação de Um Títere de Si Mesmo, DAD/UFRGS - Porto Alegre, 2012.

Examinando as operações realizadas na produção da performance Um Títere de Si Mesmo pode-se, finalmente, definir o processo como uma criação sistêmica, sendo essa caracterizada por três aspectos: funcionamento das ações criativas sob o paradigma da complexidade; emprego da técnica da colagem e construção de um hipertexto.

Em sua obra Introdução ao Pensamento Complexo, Edgar Morin esclarece muito bem o sentido de complexidade que passou a nortear nossa visão de mundo a partir da segunda metade do século XX, em substituição ao racionalismo científico e a legislação determinista da causa e efeito. Em decorrência do desenvolvimento das teorias da informação, da cibernética, da teoria dos sistemas e do conceito de auto-organização, o mundo passou, na verdade, a ser compreendido como sistema complexo, repleto de realidades possíveis.

“[...] toda realidade conhecida, desde o átomo até a galáxia, passando pela molécula, a célula, o organismo e a sociedade, pode ser concebida como sistema, isto é, associação combinatória de elementos diferentes[...] Um todo que não se reduz a soma de suas partes constitutivas, situando-se a um nível transdisciplinar. (MORIN, 2005, p. 19).

A prática artística aqui em estudo se articulou em um movimento complexo, no qual artistas de diferentes áreas se conectaram uns aos outros, trocaram, manipularam, transformaram 
e traduziram imagens diversas para outras linguagens artísticas. Tratou-se de um processo de livre associação, no qual cada artista ouviu a voz de sua própria sensibilidade e trouxe o testemunho de sua realidade para confrontar com a dos demais. A seleção e a criação de imagens jamais se fizeram levando em conta um mundo pré-concebido a ser instaurado em cena, mas sim, um mundo passível de transformação e continuação a partir da interação com os imaginários dos envolvidos no processo.

Já a fase de ensaios de Um Títere de si mesmo se fez em grande parte sob exercício da colagem, este entendido como "processo de criação que inclui a seleção, a picagem, a montagem, etc", conforme explicava Renato Cohen (2004, p.60). Dentro dessa perspectiva, os materiais concebidos de forma autônoma pelos participantes foram reunidos no espaço da cena e colados por sobreposição. Como a reconstituição de uma das imagens escolhida, denominada de Eric Sprague, onde se percebe o processo da colagem através da sobreposição de vídeo, música, texto, corpo e ação. Enquanto o performer engatinha em quatro apoios pelo palco, tendo seus movimentos ritmados pela música proposta, trechos do texto para esta imagem são projetados sobre seu corpo e, atrás do performer, outra imagem sua é projetada. A seleção de materiais e posterior colagem por sobreposição une os

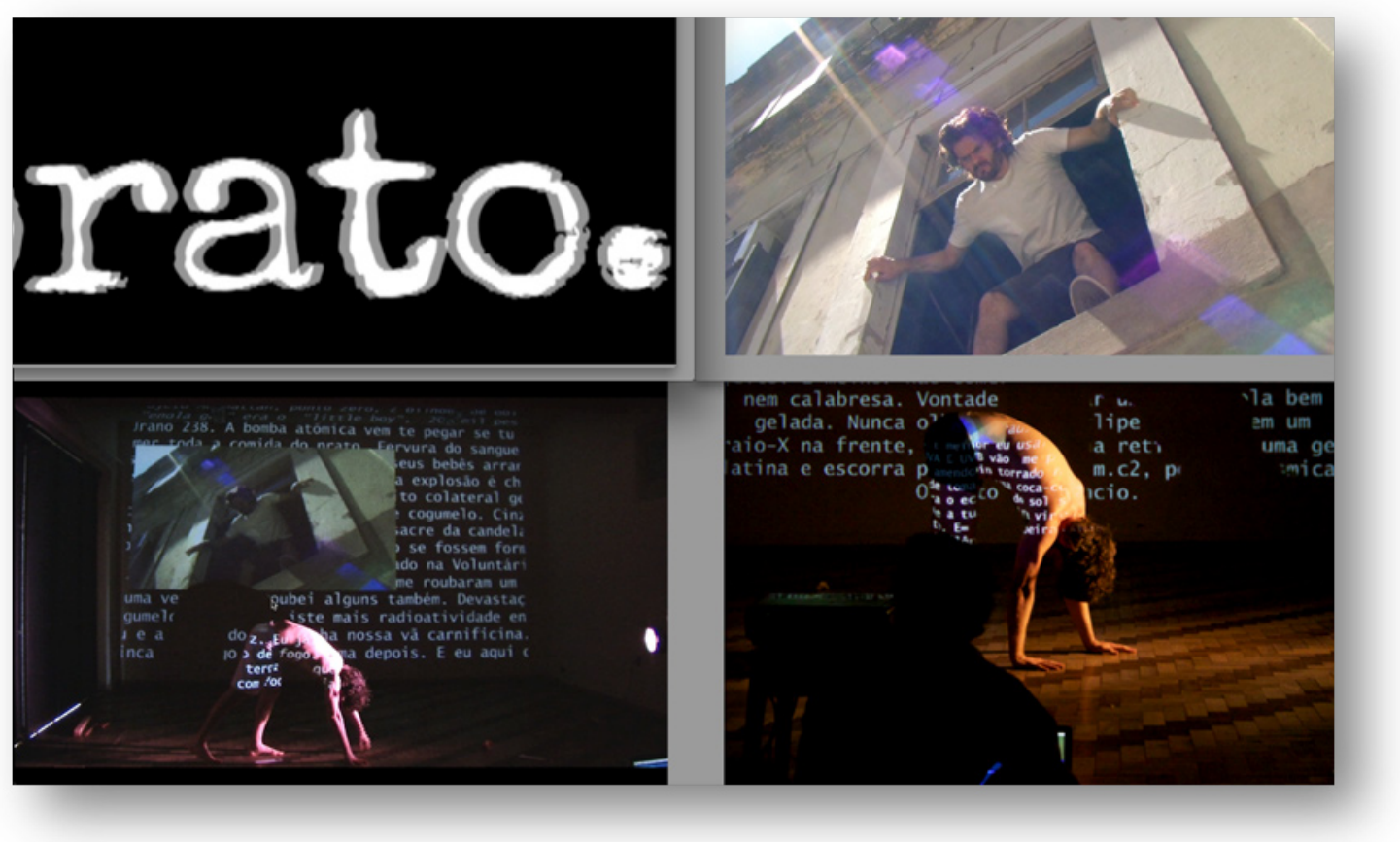

Fig. 4: Frames apresentação de Um Títere de Si Mesmo, DAD/UFRGS - Porto Alegre, 2012.

elementos, compondo um quadro cênico em movimento contínuo. Sem nenhuma amarração dramática, esvaziada de trama, Um títere de si mesmo ganha forma no cruzamento de imagens, palavras e sons, em uma rede semântica aberta associada a uma memória pessoal e coletiva em reconstrução permanente. Assim, a obra pode ser aproximada da noção de hipertexto, tal qual definição de Pierre Lévy:

Funcionalmente um hipertexto é um conjunto de nós ligados por conexões. Os nós podem ser palavras, páginas, imagens, gráficos ou partes de gráficos, sequencias sonoras, documentos complexos que podem eles mesmos ser hipertextos. Os itens de informação não são ligados linearmente, como uma corda com nós, mas cada um deles, ou a maioria, estende suas conexões em estrela, de modo reticular. (Lévy, 1990, p. 33). 
O hipertexto tem, então, a característica de maleabilidade, mutabilidade, sempre em constante transformação. Na prática aqui em estudo, as imagens se transformaram em diversas direções, como sistemas abertos, uns sobre os outros, para se encontrarem em diálogo no momento da cena. As fotografias primeiras se transformaram em notas musicais, em ações videográficas e corporais, modificando a natureza dessas imagens, prolongando-as no espaço da cena. Consequentemente, na obra, tanto as imagens primeiras, quanto aquelas que passaram por processos transformacionais, estão conectadas, repletas de passados, de referências anteriores e posteriores, compondo uma dinâmica hipertextual.

Por fim, compreende-se a prática experienciada em Um Títere de si mesmo como uma criação sistêmica, pois o processo esteve marcado pela dependência e, ao mesmo tempo, autonomia sensível dos criadores na proposição de elementos para a criação. Elementos esses, distintos que, organizados pelo princípio da colagem por sobreposição, permitiram a composição de um hipertexto cênico. Diante dele, o espectador é convidado a se deixar levar pelo fluxo, pela dinâmica do movimento dos elementos apresentados. Ele é confrontado a um sistema aberto, a uma cena organizada como obra processual, onde cada elemento tem o papel de, frequentemente, colocar o sistema em desordem, desestabilizando e impulsionando a uma auto-manutenção e nova arrumação, com leis e regras próprias.

Para encerrar, esclarecemos que, assim como grande parte do processo de criação da obra em estudo, este artigo foi produzido a quatro mãos inteiramente em espaço virtual possibilitado pelo contexto tecnológico. Construído conectando diferentes realidades em um controverso lugar, revelando nosso interesse de investir em novas formas de compartilhar pensamentos e imagens.

\section{Referências}

ARANTES, Priscila. Arte e mídia: Perspectivas da estética digital. São Paulo: Senac, 2005.

BARTHES, Roland. A Câmara Clara. Nota sobre a fotografia. Rio de Janeiro: Nova Fronteira, 1984.

COHEN, Renato. Performance Como Linguagem. São Paulo: Perspectiva, 2004.

GENETTE, Gerard. Palimpsestos. A literatura de segunda mão. Minas Gerais: Imprensa Universitária, 2006.

LEHMANN, Hans-Thies. Teatro pós-dramático. São Paulo: Cosacnaify, 1999.

LÉVY, Pierre. As Tecnologias da Inteligência. O futuro do pensamento na era da informática. São Paulo: editora 34, 2001.

LÉVY, Pierre. O Que é Virtual?. São Paulo: editora 34, 2009.

MORIN, Edgar. Introdução ao pensamento complexo. Porto Alegre: Sulina, 2011.

PEREIRA, Antonia. ISAACSSON, Marta e TORRES, Walter Lima(org.). Cena, Corpo e Dramaturgia: entre tradição e contemporaneidade. Rio de Janeiro: Pão e Rosas, 2012.

SANTAELLA, Lúcia. Culturas e artes do pós-humano. São Paulo: Paulus, 2003. 